\title{
FRANQUIA: UM BREVE ESTUDO SOBRE O CRESCIMENTO DO SETOR NO MERCADO BRASILEIRO
}

Beatriz Nunes da Silva, Caio Pedro do Nascimento Santos, Leonardo Franco Monzani, Edilene Mayumi Murashita Takenaka

Universidade do Oeste Paulista - UNOESTE, Curso Superior de Tecnologia em Gestão Comercial, Presidente Prudente, SP. E-mail: bianuunes18@gmail.com

\section{RESUMO}

A franquia (franchising) trata de um sistema alternativo de distribuição de produtos ou serviços em que o franqueador licencia sua marca ao franqueado que distribui seus produtos ou serviços. Nosso país é o quarto melhor mercado de franquias no mundo, com uma tendência de expansão promissora. $\mathrm{O}$ presente trabalho teve como objetivo identificar a analisar as características e as motivações que levam os empreendedores a optar por abraçar o sistema de franquia como instrumento empreendedor. Para tanto, este estudo foi construído através do levantamento de dados encontrados nas literaturas já existentes com a realização de pesquisas bibliográficas por meio de livros, revistas e pesquisas disponibilizados no acervo da biblioteca IES e também em sites específicos sobre o tema. Concluímos que a franquia apresenta-se como um instrumento colaborador para o desenvolvimento do mercado nacional brasileiro por apresentar características positivas para um investimento empreendedor.

Palavras-chave: Franquia. Empreendedorismo. Mercado. Desenvolvimento.

FRANCHISE: A BRIEF STUDY ABOUT THE SECTOR'S GROWTH IN THE BRAZILIAN MARKET

\begin{abstract}
:
The franchise (franchising) is an alternative system of distribution of goods or services which the franchisor licenses its brand to the franchisee that distributes its products or services. Our country is the fourth best market franchises in the world, with a promising growth trend. This study aimed to identify to analyze the characteristics and motivations that lead entrepreneurs to choose to embrace the franchise system as an entrepreneur instrument. Therefore, this study was built through the survey data found in the existing literature with conducting literature searches through books, magazines and research available in the library collection IES and also on specific sites on the subject. We conclude that the franchise presents itself as a developer tool for the development of the Brazilian domestic market by presenting positive characteristics for entrepreneurial investment.
\end{abstract}

Keywords: Franchise. Entrepreneurship. Marketplace. Development. 


\section{INTRODUÇÃO}

A cada ano, novos empreendedores arriscam seus investimentos em empreendimentos diversos na busca por sucesso financeiro e pessoal.

Esses novos empreendedores apresentam em comum, o que chamamos de perfil empreendedor, que é uma mistura de comportamento inovador com autonomia de suas ações e disposição para correr riscos.

Isso posto, julgamos que o novo empreendedor possui duas formas de empreender: investir em um negócio próprio ou arremeter em uma franquia.

O presente artigo avança sobre o ideário de montar um empreendimento com o investimento na abertura de uma loja franqueada e busca apontar suas contribuições para o crescimento do mercado brasileiro.

Segundo o Sebrae (2013, sp.), desde meados do século XIX, já se utilizava a concessão do direito de comercialização nos moldes de uma concessão como o franchising, entretanto, tal modelo chegou ao Brasil apenas na década de 1960:

Podemos dizer que o sistema de Franchising, como um modelo mais próximo do que conhecemos hoje, teve seu inicio nos Estados Unidos, por volta de 1860, quando a empresa Singer, de máquinas de costura, montou uma rede de representantes para a comercialização dos seus produtos. Iniciava-se, assim, uma forma de expansão de mercado ainda não experimentada, permitindo que a empresa passasse a ser conhecida em quase todo território americano, sem os custos para a abertura e manutenção de todos esses pontos de venda.

De acordo com dados da Associação Brasileira de Franchising (2015), atuam no País mais de 3.073 redes de franquias e existem 138.343 mil unidades franqueadas em operação, com um faturamento total de aproximadamente $\mathrm{R} \$ 139,59$ bilhões, o que corresponde a um crescimento médio de aproximadamente $10,1 \%$ em relação ao ano anterior.

A franquia apresenta-se como um negócio sistematizado em que se formaliza um acordo entre as partes: o franqueado e o franqueador. O franqueado é a pessoa jurídica que atua no mercado utilizando o nome e a marca de outra pessoa jurídica, o franqueador.

Eventualmente, o franqueador também cede ao franqueado o direito de uso de tecnologia de implantação e administração de negócio ou sistemas desenvolvidos ou detidos pelo franqueador, mediante remuneração direta ou indireta, sem ficar caracterizado vínculo empregatício.

Deste modo, buscamos através do presente projeto de pesquisa mostrar as diversas modalidade de negócios que as franquias oferecem, apresentando suas vantagens e desvantagens na abertura de uma loja franqueada, identificando as franquias que mais se expandiram nos últimos 10 anos.

\section{METODOLOGIA}

A Metodologia é a explicação minuciosa, detalhada, rigorosa e exata de toda ação desenvolvida no método do trabalho de pesquisa.

Severino (2007, p. 18) esclarece:

[...] metodologia pode ser definida como um instrumental extremamente útiul e seguro para a gestão de uma postur amadurecida frente aos problemas científicos políticos e filosóficos que nossa educação universitária enfrenta(...)São instrumentos operacionais,sejam eles técnicos ou lógicos, mediantes os quais os estudantes podem conseguir 
maior aprofundamento na ciência, nas artes ou na fiosofia, o que, afinal, é o objetivo intrínseco de ensino e da aprendizagem universitária.

As leituras nos fornecem conhecimento científico e técnico e nos proporcionam as fundamentações necessárias para compreensão do fenômeno em estudo (GIL, 2002). A pesquisa bibliográfica, segundo Lakatos \& Marconi (1985), tem por finalidade posicionar o pesquisador com o que já foi anteriormente escrito sobre determinado tema, com o objetivo de permitir o esforço paralelo na análise de suas pesquisas ou manipulação de suas informações.

Ainda, de acordo com Gil (2002, p.23): "o método científico é o conjunto de processos ou operações mentais que se deve empregar na investigação da pesquisa. É a linha de raciocínio seguida durante o seu processo".

Dessa forma, o presente artigo foi desenvolvido a partir de revisão bibliográfica com levantamento de dados junto à documentação indireta em fontes primárias e secundárias. Fizemos uso da pesquisa descritiva e explicativa em que realizamos o estudo, a análise, o registro e a interpretação dos fatos com maior investimento em síntese, teorização e reflexão a partir do objeto de estudo visando identificar os fatores que contribuem para a ocorrência dos fenômenos ou variáveis que afetam o processo.

\section{RESULTADOS}

Sabemos que, nas últimas décadas, as franquias apresentam-se como uma tendência forte no mercado brasileiro e, por conta de seu crescimento, o sistema brasileiro de franquias é o $4^{\circ}$ maior do mundo em marcas.

Possuir o próprio negócio sempre fez parte do ideal do trabalhador brasileiro e o sistema de franquias apresenta a possibilidade de estabilidade econômica em um empreendimento cujo modelo já foi previamente testado.

Segundo Dornelas (2001) e Hisrish; Peters (2004), o empreendedor é uma pessoa inovadora, capaz de criar algo novo dedicando tempo e esforços necessários, assumindo riscos financeiros, psíquicos sociais correspondentes.

"Uma das características mais representativa dos brasileiros, como todos sabem, é o desejo de empreender." (GUETTA et al,2013, p.29)

As franquias atendem a essa premissa ao transferir o conhecimento de quem sabe fazer para quem quer aprender e fazer igual.

Afinal, o que vem a ser uma franquia?

Segundo Barroso (1997, p.19):

Franchising [...] é o sistema de distribuição mais bem conhecido até hoje, em que os direitos de uso da marca e da tecnologia de negócios de uma empresa (franqueadora) são cedidos, contratualmente, a terceiros (franqueados) mediante determinadas condições: pagamento de uma taxa para ingresso no sistema do franqueador (taxa de franquia ou franchising) e de royalties, determinando percentual sobre suas vendas que 0 franqueado paga, periodicamente, ao franqueador.

O sistema de franquia é bem-sucedido por várias razões e, a principal, é seu fundamento muito simples: a concessão dos direitos de uso de uma marca associada à concessão dos direitos de venda de produtos ou serviços.

De acordo com estudo realizado por Guetta (2013, p. 48), pondera-se:

Franquia empresarial (franchising) é o sistema pelo qual um franqueador cede ao franqueado o direito de uso de uma marca ou patente, associado 
ao direito de distribuição exclusiva ou semiexclusiva de produtos ou serviços e, eventualmente, também ao direito de uso de tecnologia de implantação e administração de negócio ou sistema operacional desenvolvidos ou detidos pelo franqueador mediante remuneração direta ou indireta, sem que, no entanto, fique caracterizado vínculo empregatício.

O modelo de franquia é uma boa opção para quem quer abrir seu próprio negócio, ela fornece ao franqueador o produto ou serviço auxiliando na abertura da empresa dando suporte administrativo e treinamentos, além de já adquirir um produto conhecido no mercado. $O$ franqueado sempre poderá contar com o apoio do franqueador, que já possui experiência e que vai transmitir. Apesar da autonomia não ser total, o franqueado possui independência jurídica ou financeira em relação ao franqueador. Costuma-se afirmar que a franquia é um tipo de negócio seguro, bem planejado para fazer sucesso que possue marca consolidada e público fiel.

A tabela 1, a seguir, mostra de forma resumida, as vantagens e desvantagens para franqueados e franqueadores, segundo estudos de Plá (2001):

Tabela 01. Vantagens e desvantagens para franqueados e franqueadores

\begin{tabular}{|c|c|}
\hline Franchising: Vantagens & Franchising: Desvantagens \\
\hline $\begin{array}{l}\text { Para o franqueador: } \\
\text { - Propicia expansão do negócio com } \\
\text { recursos de terceiros; } \\
\text { - Possibilita economia de escala; } \\
\text { - Dilui responsabilidade com a } \\
\text { concorrência; } \\
\text { - Proporciona fortalecimento da marca }\end{array}$ & $\begin{array}{l}\text { Para o franqueador: } \\
\text { - Apresenta dificuldades de manutenção } \\
\text { dos padrões operacionais e disciplina do } \\
\text { franqueado; } \\
\text { - Denota problemas no processo de } \\
\text { quebra de vínculo com o franqueado; } \\
\text { - Mostra complexidade quanto à divisão } \\
\text { de ganhos e formação de concorrência } \\
\text { potencial }\end{array}$ \\
\hline $\begin{array}{l}\text { Para o franqueado: } \\
\text { - Favorece a atuação em um mercado } \\
\text { competitivo e utilização de uma marca } \\
\text { consolidada com tecnologia e } \\
\text { metodologia já testada; } \\
\text { - Possibilita a minimização dos riscos de } \\
\text { abertura de um negócio próprio }\end{array}$ & $\begin{array}{l}\text { Para o franqueado: } \\
\text { - Apresenta oportunidade reduzida de } \\
\text { iniciativas individuais; } \\
\text { - Aponta para custos com a marca e a } \\
\text { metodologia além dos riscos do } \\
\text { franqueador fracassar }\end{array}$ \\
\hline
\end{tabular}

Fonte: Plá (2001, p. 30)

Organizado pelos autores.

Dessa forma, podemos observar que há situações vantajosas e desvantajosas para ambas as posições: a do franqueado e a do franqueador. Situações que devem ser observadas pelo empreendedor antes de sua tomada de decisão sobre o investimento em um sistema de franquia.

\section{DISCUSSÃO}

Podemos afirmar que, a atratividade e o sucesso da franquia será proporcional à força reconhecida de uma marca quanto mais diferenciados e atraentes forem os produtos e serviços associados a ela.

A franquia é concedida do empresário, dono da marca (franqueador) para o pequeno e médio empresário, ou até mesmo para aquele que queira ter seu próprio negócio (franqueado). Após a marca ser concedida, o franqueado tem o direito do uso do nome da marca e também da 
tecnologia de implantação e administração de negócio, ou sistema operacional sob regras e condições pré-estabelecidas por contrato e compartilhando os resultados.

Entretanto, vários autores concordam em um ponto em comum em que, através da franquia, o franqueador poderá ingressar em mercados diversos nos quais dificilmente investiria se dependesse de seus recursos próprios pois, seria muito arriscado. Em contrapartida, para o franqueado, o investimento em uma franquia estruturada, com um produto já consolidado e metodologias que se provem promissoras, apresenta um risco menor do capital investido e maior probabilidade de êxito profissional.

\section{CONCLUSÃO}

Ao analisarmos as vantagens e desvantagens do sistema de franquias para franqueados e franqueadores, pudemos observar que há dificuldades que devem ser cuidadosamente analisadas para que esse sistema continue a crescer no mesmo ritmo de crescimento apresentado nos últimos dez anos.

Os franqueadores devem procurar potenciais franqueados capacitados a enfrentar dificuldades ligadas ao gerenciamento do empreendimento, disciplina e manutenção de processos operacionais.

Os franqueados devem atentar para os fatos que envolvem investir em um sistema de franquia pois, apesar do risco reduzido devido à adoção de um modelo previamente testado relacionado a uma marca já conhecida, os mesmos ficam atados aos custos ligados a metodologia da franquia adotada além da oportunidade reduzida de iniciativas individuais.

Entretanto, o espírito empreendedor tem prevalecido e a prova disso é o crescimento do setor em números comprovados pela Associação Brasileira de Franchising (ABF).

\section{REFERÊNCIAS}

ABF. Associação Brasileira de Franchising. Disponível em: <www.abf.com.br $>$. Acesso em: 10 abr. 2016.

BARROSO, L. F. Franchising e Direito. São Paulo: Atlas, 1997.

BETO FILHO et al. Franchising: apresenta com os especialistas = Franchising: learnfronthe experts . [e1. ed. bilíngue. - Rio de Janeiro: ABF-Rio, 2013

DORNELAS, J. C. de A. Empreendedorismo: Transformando Idéias em Negócios. Rio de Janeiro: Campus, 2001

GIL. A. C. Métodos e Técnicas de pesquisa social. 4 ed. São Paulo: Atlas, 1994

GUETTA, A. et al. Franchising: apresenta com os especialista = Franchising: learn fron the experts.[1 ed. Rio de Janeiro: ABF - RIO, 2013

GUETTA, A. et al. Franchising: apresenta com osespecialista = Franchising: learn fron the experts. [1 ed. Rio de Janeiro: ABF - RIO, 2013

HISRICH, R D; PETERS M.P. Empreendedorismo, 5aed;. Porto Alegre, Bookman, 2004.

LAKATOS, E. M.; MARCONI, M. Fundamentos de metodologia cientifica. 3.ed.rev.e ampl. São Paulo: Atlas, 1991. 
Marcel Luiz Pleul e Rodolfo Coser Maiochi, EMPREENDEDORISMO E FRANQUIAS:um estudo com franqueador e franquedos de uma rede de fast food. Disponível em:

http://www.webartigos.com/artigos/empreendedorismo-e-franquias-um-estudo-com-

franqueador-e-franqueados-de-uma-rede-de-fast-food/53596/. Acesso em 03/07/2016.

PLÁ, Daniel. Tudo Sobre Franchising. São Paulo: Senac, 2001.

SCHWARTZ, J. C. O que você precisa saber - Rio de Janeiro; Qualitymark, 2008.

SEVERINO, A.J. Metodologia do trabalho científico. 23. ed. São Paulo: Cortez, 2007. 